\title{
Duration of Intubation After Gastric Pull up Operation in Young Children
}

\author{
Mohammad Fathi ${ }^{1}$; Bahador Bagheri ${ }^{2}$; Sajjad Razavi ${ }^{1}$; Alireza Mahdavi ${ }^{1}$; Sara Salarian ${ }^{1, *}$ \\ ${ }_{1}^{1}$ Department of Anesthesiology, Mofid Children Hospital, Shahid Beheshti University of Medical Sciences, Tehran, IR Iran \\ ${ }^{2}$ Cancer Research Center, Department of Pharmacology, Semnan University of Medical Sciences, Semnan, IR Iran \\ ${ }^{*}$ Corresponding author: Sara Salarian, Department of Anesthesiology, Mofid Children Hospital, Shahid Beheshti University of Medical Sciences, Tehran, IR Iran. Tel: +98-2122227021, \\ Fax:+98-2122220254, E-mail: Sarasalarian@yahoo.com
}

Received: September 29, 2014; Revised: January 4, 2015; Accepted: January 21, 2015

\begin{abstract}
Background: Gastric pull up is performed in patients with esophageal atresia (EA) and caustic injuries. In general, elective gastric pull up is performed when patients weigh above $10 \mathrm{~kg}$. Obesity can cause respiratory compromises and lengthen duration of hospitalization and children may have poor general condition.

Objectives: Our goal was to investigate whether patients who weighed less than $10 \mathrm{~kg}$ had better clinical status after gastric pull up operation compared to those who were more than $10 \mathrm{~kg}$.

Patients and Methods: We retrospectively reviewed the records of 90 patients who underwent gastric pull up due to esophageal atresia in Mofid Children Hospital, Tehran, Iran. Clinicopathological features of children were studied according to their weights on the operation day.

Results: The mean age was $5 \pm 2$ years in patients who were above $10 \mathrm{~kg}$ and $3 \pm 1$ years in those less than $10 \mathrm{~kg}$. Patients who were less than $10 \mathrm{~kg}$ had shorter duration of intubation, compared to the children who were above $10 \mathrm{~kg}(\mathrm{P}<0.05)$.

Conclusions: Elective gastric pull up can be performed for children who are not above $10 \mathrm{~kg}$. In such settings, the risk of respiratory infections and other complications would be significantly reduced because of shorter duration of intubation.

Keywords: Children; Esophageal Atresia; Intubation
\end{abstract}

\section{Background}

Esophageal replacement in childhood is one of the major surgical challenges and is undertaken mainly for benign conditions. Esophageal atresia (EA) and caustic injuries are usual indications for esophageal replacement. Gastric transposition (gastric pull up), colon transposition and gastric tube are used for esophageal replacement $(1,2)$. The neo-esophagus should allow normal oral feeding, absence of refluxes and be able to function well for the lifetime of patient (2). EA can cause severe complications for children, such as infection, tracheomalacia and esophageal strictures (3). EA is the most common indication for gastric transposition. However, esophageal stenting has gained prominence during the recent years. Preservation of native esophagus is desirable and can be achieved in most cases. However, some patients with long gap esophageal atresia would require esophageal replacement. In addition, a number of those patients managed with primary repair would require an esophageal substitution as a result of complications of the primary procedure or development of refractory gastroesophageal reflux, persistent stricture, and/or esophageal dysfunction. In those patients, preservation of esophagus may be futile. The gastric pull up establishes effective gastrointestinal continuity with few long-term complications (4-6). Currently, gastric pull up is performed when a patient is over $10 \mathrm{Kg}$. In such conditions, patients may have obesity and other important complications, like long time intubation, which is the potential risk factor of ventilator-associated pneumonia (VAP). Of note, VAP is a leading cause of morbidity and mortality.

\section{Objectives}

The goal of this study was to evaluate whether elective gastric pull up is safe in children less than $10 \mathrm{~kg}$. We hypothesized that early operation of such patients could reduce the likelihood of VAP and other complications.

\section{Patients and Methods}

We retrospectively reviewed the records of 90 patients who underwent gastric transposition for esophageal reconstruction between 2005 and 2013 regarding demographics, initial esophageal disease, previous treatment and specifics of the gastric transposition procedure, complications and follow-up. The exclusion criteria were as follows: inflammatory conditions, respiratory diseases, advanced hepatic or renal disease and malignant neoplastic diseases. None of the patients had other gastrointestinal diseases. The local ethical committee approved the study. 
Fathi M et al.

\subsection{Data Analysis}

Data are reported as mean \pm SD or numbers (percentage). Categorical variables were compared using one-way analysis of variance. Means were compared by Wilcoxon signed rank test. Differences at the level of $\mathrm{P}<0.05$ were considered statistically significant. All analyses were performed using SPSS 16.0 (IBM, US).

\section{Results}

\subsection{Clinical Characteristics}

Baseline characteristics of patients are shown in Table 1 From a total of 90 patients, 38 patients weighed less than $10 \mathrm{~kg}$ and 52 patients above $10 \mathrm{~kg}$. No significant difference was observed in clinical characteristics of the study subjects.

\subsection{Duration of Intubation}

As shown in Table 2, patients above $10 \mathrm{~kg}$ significantly had longer duration of intubation compared to those who were thinner $(\mathrm{P}<0.05)$.

\begin{tabular}{lccc}
\hline \multicolumn{4}{l}{ Table 1. Clinical Characteristics of the Study Subjects ${ }^{\mathrm{a}}$} \\
\hline Characteristic & Below 10 $\mathbf{~ k g}(\mathbf{n}=\mathbf{3 8})$ & Above $\mathbf{~} \mathbf{~ k g}(\mathbf{n}=\mathbf{5 2})$ & P Value \\
\hline $\begin{array}{l}\text { Age, } \mathbf{y} \\
\text { Males }\end{array}$ & $5 \pm 2$ & $3 \pm 1$ & 0.06 \\
$\begin{array}{l}\text { Concomitant } \\
\text { disorders }\end{array}$ & 63 & 54 & 0.07 \\
$\begin{array}{l}\text { Cardiorespiratory } \\
\text { Renal }\end{array}$ & 22 & 18 & \\
\hline \multicolumn{1}{l}{ Neuromuscular } & 19 & 18 & 0.5 \\
\hline a Data are shown as \% or Mean \pm SD. & 7 & 0.1 \\
\hline
\end{tabular}

Table 2. Duration of Intubation in the Study Subjects ${ }^{a}$

\begin{tabular}{lcc}
\hline Group & Sample Size & Duration of Intubation, Day \\
\hline Below $10 \mathrm{~kg}$ & 38 & $4 \pm 2^{\mathrm{b}}$ \\
Above $10 \mathrm{~kg}$ & 52 & $8 \pm 1$ \\
\hline
\end{tabular}

a Data are shown as number or Mean \pm SD

b $\mathrm{P}<0.05$.

\section{Discussion}

Stomach replacement has advantages of having a single anastomosis in the neck or mediastinum; a very good blood supply and replacing the whole length of the esophagus with a low risk of leak and stricture. Oral feedings and appropriate weight gain are achieved in most children, if successful (7-9). In this approach, the stomach occupies a large space in the chest of small children and has a potential for causing significant respiratory compromise and possibly VAP. It could also be a source of recurrent aspirations from gastroesophageal reflux
(10). As we showed, obese children had longer duration of intubation. It may last for 10 up to 15 days. Interestingly, most of children less than $10 \mathrm{~kg}$ extubated after one day and few cases extubated after the operation. This is more important in children who have concurrent cardio-respiratory disease, neuromuscular disorders or renal failure. Other conditions like duration of operation, use of immunosuppressive and $\mathrm{H} 2$ blockers, poor health status of the oral cavity, surgical traumas, NG (Nasogastric) tube and sedation can potentially increase the risk of VAP (11). Corrosive ingestion results in substantial penetrating injury. Esophageal strictures are reported in up to $40 \%$ of patients with corrosive injury. Perforation rates are high for corrosive strictures. Ingestion of corrosives is a worldwide problem, especially in developing countries (12). Long-term follow-up of children underwent gastric pull up is essential because of gradual changes in the function of graft, strictures at the anastomosis and unknown risks of the Barrett's esophagus $(13,14)$. In the current study, three patients died because of esophageal rupture and following sepsis. In conclusion, our results showed that elective gastric pull up could be performed for children who are not above $10 \mathrm{~kg}$. In such settings, the risk of VAP and other compromises would be significantly reduced; however, long-term follow up is mandatory.

\section{Acknowledgements}

We wish to thank the efforts of staff of Mofid hospital.

\section{References}

1. Spitz L. Esophageal atresia. Lessons I have learned in a 40-year experience. J Pediatr Surg. 2006;41(10):1635-40.

2. Gross RE. The surgery of infancy and chilhood.Philadelphia: WB Saunders; 1953.

3. Harmon MC, Coran AG. Congenital anomalies of the esophagus.Philadelphia, PA: Elsevier Saunders; 2012.

4. Holcomb G3, Rothenberg SS, Bax KM, Martinez-Ferro M, Albanese CT, Ostlie DJ, et al. Thoracoscopic repair of esophageal atresia and tracheoesophageal fistula: a multi-institutional analysis. Ann Surg. 2005;242(3):422-8.

5. Bax NM, van der Zee DC. Jejunal pedicle grafts for reconstruction of the esophagus in children.J Pediatr Surg. 2007;42(2):363-9.

6. Kimura K, Nishijima E, Tsugawa C, Collins DL, Lazar EL, Stylianos $S$, et al. Multistaged extrathoracic esophageal elongation procedure for long gap esophageal atresia: Experience with 12 patients. J Pediatr Surg. 2001;36(11):1725-7.

7. Bax NMA, Zee DC. The thoracoscopic approach to esophageal atresia with distal fistula. In: Bax NMA, Georgeson KE, Rothenberg SS, Valla JS, Yeung CK editors. Endoscopic surgery in children and infants.. Berlin: Springer-Verlag; 2008. pp. 199-205.

8. Kovesi T, Rubin S. Long-term complications of congenital esophageal atresia and/or tracheoesophageal fistula. Chest. 2004;126(3):915-25.

9. Lundell LR, Dent J, Bennett JR, Blum AL, Armstrong D, Galmiche $\mathrm{JP}$, et al. Endoscopic assessment of oesophagitis: clinical and functional correlates and further validation of the Los Angeles classification. Gut. 1999;45(2):172-80.

10. Van Gysel D, De Boeck K, Lerut T. Pulmonary status during child hood after corrected esophageal atresia. Eur Respir J. 1992;15:103s.

11. Konkin DE, O'Hali W A, Webber EM, Blair GK. Outcomes in esophageal atresia and tracheoesophageal fistula.J Pediatr Surg. 2003;38(12):1726-9. 


\section{Fathi M et al.}

12. Hamza AF, Abdelhay S, Sherif H, Hasan T, Soliman H, Kabesh A, et al. Caustic esophageal strictures in children: 30 years' experience. J Pediatr Surg. 2003;38(6):828-33.

13. Malmstrom K, Lohi J, Lindahl H, Pelkonen A, Kajosaari M, Sarna S, et al. Longitudinal follow-up of bronchial inflammation, respi- ratory symptoms, and pulmonary function in adolescents after repair of esophageal atresia with tracheoesophageal fistula. JPediatr. 2008;153(3):396-401.

14. Spitz L, Kiely E, Pierro A. Gastric transposition in children--a 21year experience. J Pediatr Surg. 2004;39(3):276-81 